\title{
SOCIAL MEDIA AND ITS ROLE IN MARKETING
}

\author{
Vinod Durgam \\ Hyderabad, India
}

\begin{abstract}
Social Media, today, is among the 'best opportunities available' to a brand for connecting with prospective consumers. Social media is the medium to socialize. These new media win the trust of consumers by connecting with them at a deeper level. Social media marketing is the new mantra for several brands since early last year. Marketers are taking note of many different social media opportunities and beginning to implement new social initiatives at a higher rate than ever before. Social media marketing and the businesses that utilize it have become more sophisticated. One cannot afford to have no presence on the social channels if the competitor is making waves with its products and services. The explosion of social media phenomenon is as mind boggling as that and the pace at which it is growing is maddening. Global companies have recognized social media marketing as a potential marketing platform, utilized them with innovations to power their advertising campaign with social media marketing. This paper discusses about the concepts of social media and social media marketing and other aspects like the growth and benefits, role and relevance of social media in marketing, social media marketing strategies. It also presents an overview on social media marketing in India.
\end{abstract}

Key words: Social Media, Social Media Marketing, Growth and Benefits of Social Media, Social Media Marketing Strategy, Social Media Marketing in India.

Cite this Article: Vinod Durgam, Social Media and Its Role in Marketing. International Journal of Advanced Research in Management, 9(2), 2018, pp. 01-10. http://iaeme.com/Home/issue/IJARM?Volume=9\&Issue=2

\section{INTRODUCTION}

Social media is hot. Social Media is now the trend. And for businesses it represents a marketing opportunity that transcends the traditional middleman and connects companies directly with customers. This is why nearly every business on the planet - from giants like Starbucks and IBM to the local ice cream shop-are exploring social media marketing initiatives. A year ago, businesses were uncertain about social media. Now it's here to stay and companies are rapidly adopting social media marketing. Much like email and websites first empowered businesses, social media is the next marketing wave. 
Social media marketing is marketing using online communities, social networks, blog marketing and more. It's the latest "buzz" in marketing. India is probably among the first proponents of social media marketing. These days, the organizational cause has replaced the social cause as companies seek to engage with their audience via the online platforms.

The explosion of social media phenomenon is as mind boggling as that and the pace at which it is growing is maddening. Trust and goodwill are the basis of social networking, and by marketing in the realm of social media these fundamental notions need to be adhered. It is probably the only marketing platform that encourages fool proof communication and accountability among sellers as well as consumers. Global companies have recognized Social Media Marketing as a potential marketing platform, utilized them with innovations to power their advertising campaign with social media marketing.

\section{SOCIAL MEDIA}

Social media is engaging with consumers online. According to Wikipedia, social media is internet-based tools for sharing and discussing information among human beings. Social media is all about networking and networking in a way that espouses trust among parties and communities involved. Any website which allows user to share their content, opinions, views and encourages interaction and community building can be classified as a social media. Some popular social media sites are: Facebook, YouTube, Twitter, Digg, MySpace, StumbleUpon, Delicious, Scribd, Flickr etc.

The meaning of the term 'social media' can be derived from two words which constitute it. Media generally refers to advertising and the communication of ideas or information through publications/channels. Social implies the interaction of individuals within a group or community. Taken together, social media simply refers to communication/publication platforms which are generated and sustained by the interpersonal interaction of individuals through the specific medium or tool. Wikipedia has a general definition of the term: Social Media is the democratization of information, transforming people from content readers into content publishers. It is the shift from a broadcast mechanism to a many-to-many model, rooted in conversations between authors, people, and peers.

Social media uses the "wisdom of crowds" to connect information in a collaborative manner. Social media can take many different forms, including Internet forums, message boards, weblogs, wikis, podcasts, pictures, and video.

Social media is made up of user-driven websites that are usually centered on a specific focus $($ Digg $=$ news $)$ or feature (del.icio.us = bookmarking). Sometimes, the community itself is the main attraction (Facebook and Myspace $=$ networking)

Social media are media for social interaction, using highly accessible and scalable publishing techniques. Social media uses web-based technologies to turn communication into interactive dialogues. Andreas Kaplan and Michael Haenlein define social media as "a group of Internet-based applications that build on the ideological and technological foundations of Web 2.0, which allows the creation and exchange of user-generated content."

Social media is the medium to socialize. They use web-based technology to quickly disseminate knowledge and information to a huge number of users. They allow creation and exchange of user-generated content. Facebook, Twitter, Hi5, Orkut and other social networking sites are collectively referred social media.

Social media represents low-cost tools that are used to combine technology and social interaction with the use of words. These tools are typically internet or mobile based like Twitter, Facebook, MySpace and YouTube. 
There are two benefits of social media that are important to businesses, they include:

1. Cost reduction by decreasing staff time.

2. Increase of probability of revenue generation.

Social media enables companies to:

- Share their expertise and knowledge.

- Tap into the wisdom of their consumers.

- Enables customers helping customers.

- Engages prospects through customer evangelism.

Thus the benefits of social media include: brand reach and awareness, consumer interactions through transactions, referrals and reputation management.

\subsection{Social media marketing}

Social media marketing consists of the attempt to use social media to persuade consumers that one's company, products and/or services are worthwhile. Social media marketing is marketing using online communities, social networks, blog marketing and more. Lazer and Kelly's (1973) define social marketing as "concerned with the application of marketing knowledge, concepts, and techniques to enhance social as well as economic ends. It is also concerned with the analysis of the social consequences of marketing policies, decisions and activities."

Social media marketing is not merely about hitting the frontpage of Digg or any other social news website. It is a strategic and methodical process to establish the company's influence, reputation and brand within communities of potential customers, readers or supporters.

\subsection{Growth of social media marketing}

A recent study, "The State of Small Business Report," sponsored by Network Solutions, LLC and the University of Maryland's Robert H. Smith School of Business, points to economic struggles as the catalyst for social media's rapid popularity. The study results show that social media usage by small business owners increased from $12 \%$ to $24 \%$ in just the last year, and almost 1 out of 5, actively uses social media as part of his or her marketing strategy. In 2009, only $23 \%$ of marketers were using social media for years. Now that number has grown to $31 \%$. Here's a breakdown of what the small businesses reported as the main uses of social media marketing:

- $75 \%$ have a company page on a social networking site.

- $69 \%$ post status updates or articles of interest on social media sites.

- $57 \%$ build a network through a site such as LinkedIn.

- $54 \%$ monitor feedback about the business.

- $39 \%$ maintain a blog.

- $26 \%$ tweet about areas of expertise.

- $16 \%$ use Twitter as a service channel.

According to the study, different industries are adopting social media marketing at different rates, and while many industries have started using social media marketing in their efforts to reach more customers, many still have not positioned it as their top priority.

A research shows that charitable organizations are still outpacing the business world and academia in their use of social media. In a study conducted in 2008, a remarkable eighty-nine 
percent of charitable organizations are using some form of social media including blogs, podcasts, message boards, social networking, video blogging and wikis. A majority (57\%) of the organizations are blogging. Forty-five percent of those studied report social media is very important to their fundraising strategy. While these organizations are best known for their nonprofit status and their fundraising campaigns, they demonstrate an acute, and still growing, awareness of the importance of Web 2.0 strategies in meeting their objectives.

Back in 2013, marketers had already planned on devoting more money to social media. However, in 2017, marketers reported that they plan to allocate about one-third to half of their marketing budgets to social media marketing in the next 5 years. This is a definite increase from the 2013 projections. The study features the following comparison from 2013 to 2022:

Current marketing budget spending on social media:

2013: $23.2 \%$

2014: $28.7 \%$

2015: $31.4 \%$

2016: $33.3 \%$

2017: $34.5 \%$

Marketing budget spending on social media in the next 12 months:

2017: $34.5 \%$

2018: $43.5 \%$

Marketing budget spending on social media in the next 5 years:

2018: $43.5 \%$

2019: $47 \%$

2020: $49.9 \%$

2021: $52.1 \%$

2022: $53.9 \%$

It can be understood that even though many are still experimenting and learning how best to use social media tools, these results indicate that marketers think social media marketing is here to stay and will play an increasingly important role in their work in acquiring and retaining customers in the future.

\subsection{Benefits of social media marketing:}

Significantly different from conventional marketing strategies, Social Media Marketing (SMM) offers three distinct advantages. One, it provides a window to marketers to not only present products / services to customers but also to listen to customers' grievances and suggestions. Two, it makes it easy for marketers to identify various peer groups or influencers among various groups, who in turn can become brand evangelist and help in organic growth of a brand. And, three, all this is done at nearly zero cost (as compared to conventional customer outreach programmes) as most of the social networking sites are free.

Social media marketing helps in:

- Generating exposure to businesses.

- Increasing traffic/subscribers.

- Building new business partnerships.

- Rise in search engine rankings.

- Generating qualified leads due to better lead generation efforts.

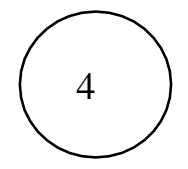


- Selling more products and services.

- Reduction in overall marketing expenses.

Companies in the west are investing increasingly in SMM to get in touch with their customers. They are indulging in constant interaction with their prospects in order to understand their needs and hence make products better. It's the best way to learn from your customers about their needs and your own shortcomings. However, SMM is a very personalized way of advertising and promotions can be targeted only to particular groups which are interested in a particular domain, quite unlike conventional advertising.

\subsection{Understanding the Relevance of Social Media in Marketing:}

The role of social media in marketing is to use it as a communication tool that makes the companies accessible to those interested in their product and makes them visible to those that don't know their product. It should be used as a tool that creates a personality behind their brand and creates relationships that they otherwise may never gain. This creates not only repeatbuyers, but customer loyalty. Fact is social media is so diversified that it can be used in whatever way best suits the interest and the needs of the business.

According to 2010 Social Media Marketing Industry Report 2010, a majority of marketers (56\%) are using social media for 6 hours or more each week, and nearly one in three invest 11 or more hours weekly. Twitter, Facebook, LinkedIn and blogs were the top four social media tools used by marketers, in order. A significant $81 \%$ of marketers plan on increasing their use of blogs. A majority of the marketers are employing social media for marketing purposes and small businesses were slightly more likely to use social media. $76 \%$ of marketers are spending at least 4 hours each week on their social media marketing efforts.

In the present context, it is increasingly becoming pertinent for companies to (1) build a favorable base of consumers, and (2) involve them in decision making. According to Softpedia, during the last quarter of 2009, 86 percent of online retailers in US had a Facebook page. It was expected that this figure would reach 99 percent very soon. During this same period, e-marketer pointed that 65 percent of its surveyed online retailers were active on Twitter. Another 26 percent were planning to incorporate Twitter in their plans. E-marketer projects that by 2011, 91 percent of online retailers will be Twitter ready and all of them will have a Facebook page. Presently, greater than 700 thousands businesses have an active Facebook page. And around 80 thousand web portals are Facebook Connected presently.

Social media gives marketers a voice and a way to communicate with peers, customers and potential consumers. It personalizes the "brand" and helps you to spread the message in a relaxed and conversational way.

Adult beverage companies, exotic automobile manufacturers, pastry shops have been using social media tool. Pepsi Coke, Nokia and many of the top brands have effectively used social media for achieving their business objectives. Few companies that have become involved in social media are:

Absolut Vodka - Online Video on YouTube and Using Facebook to house their Top Bartender fan page.

BMW - Utilizing Facebook to promote their 1-Series Road Trip and they have created a Rampenfest Page for fans.

Dunkin Donuts - They've found value in social media and have set up a microblogging Twitter account.

General Motors - GM leverages the social media to improve the online equity of its brand and make consumers feel more connected. 
Until recent past, social media effectively served as another customer outreach activity of organizations - essentially building brand awareness and generating leads. However, trends are now changing towards utilizing social media for positively impacting sales. A mindset shift towards making social media a committed engagement channel is already underway. An analysis by Wetpaint and Altimeter - engagementdb.com, concurs that the most successful companies on social platforms were maintaining profiles on 7 or more channels.

\subsection{The Pervasiveness of Social Media}

Social media is no more a fancy term; its popularity can be deduced from the findings of the latest PEW Research - as much as 70 percent of the economically active population is well entrenched in to the social media space. Similar statistics, albeit from a different source eMarketer, further corroborates this notion; 46 percent of people in age group of $44-62$ years and around 61 percent under category 27 to 43 years are socially networked.

\subsection{Role of social media in marketing}

Social media is now increasingly becoming an ingrained aspect of political campaigns, national defense strategies, public policy, public relations, brand management and even intra company communication.

Since the major task of marketing as tool used to inform consumers about the company'sproducts, who they are and what they offer, social marketing plays an important role in marketing.

Social media can be used to provide an identity about the companies and the products or services that they offer.

- Social media helps in creating relationships with people who might not otherwise know about the products or service or what the companies represent.

- Social media makes companies "real" to consumers. If they want people to follow them they need not just talk about the latest product news, but share their personality with them.

- Social media can be used to associate themselves with their peers that may be serving the same target market.

- Social media can be used to communicate and provide the interaction that consumers look for.

Why businesses need to consider social media marketing services?

Size: Facebook has over 250 million users globally. On an average, 70-100 tweets happen by the second. An average user on Facebook has 120 friends. This is the kind of enormity Social networking sites espouse and with this comes the license to communicate powerfully. But when such large numbers are involved, there is a danger of something going wrong and when it does, it happens in a big way. An expert should be hired to do what is best for business.

Transparency: No cheat code involved. No black hat techniques allowed. Everything that happens in the social networking landscape is fool proof. Companies cannot fake authenticity in an attempt to get more people involved. Members can choose to associate with the company or opt out. Opinions made on social networking platforms are taken seriously and the more authoritative the companies get, more seriously they are taken.

Reach: It is possible to make mark globally and do it quickly using social networking sites.

Boost website traffic: Social media is probably the fastest and easiest means of redirecting traffic to company's website. By simply placing their website URL in their profile, the company can have all their profile visitors check out their website and a percentage of traffic is sure to get converted in course of time. This is the virtual way version of "word-of mouth". 
Branding: Buying a candy may have been impulsive all your life, but if it is discussed on a social networking site, there is likely to get brand conscious even a candy. Social media is a smart way to build brands. Social media platforms are known to be one of the most powerful and fast means of branding. Some of the big brands like Coke, Ford, Dell, IBM, Burger King are some of the well known brands have powerfully used social media platforms to endorse themselves.

\subsection{Barriers to Implementation of Social Media at companies}

On the other hand, social media use scenario is more encouraging at small businesses. According to the State of Small Business Report, social media usage by small businesses increased from 12 percent to 24 percent in the last year. Further, almost 20 percent of small businesses actively employ social media as an integral part of the marketing strategy. In fact small businesses are currently allocating $6 \%$ of their marketing budgets to social media. It is expected that this is expected to reach 10 percent by 2011 and further to around 18 percent over the next 5 years. Some of the findings from the survey are particularly encouraging from business via social media point of view, these include:

- 75 percent of small businesses have presence on a social networking site

- 54 percent are monitoring feedbacks

- 69 percent post updates or interesting articles on social media sites

Those are some mind boggling numbers, especially after the viewing the depth of social media penetration across big companies. But what is most striking from the two surveys is the fact that while nearly 70 percent of Fortune 100 companies are virtually inactive. However, a similar percentage of small businesses are buzzing with activity on social media. Nonetheless statistics aside, it is high time, that businesses, irrespective of their size have a social media plan that has 3 C's in it, viz (1) a Companywide engagement strategy that (2) ensures Conversations with consumers, and (3) Causes user loyalty across social networks.

\subsection{Social Media Marketing in India - An Overview}

India has 71 million active internet users. Social Media is really picking up new heights in India. According to the 2010 Regus Global Survey of business social networking, India tops the usage of social networking by business - it has the highest activity index, 127, far more than the US' 97 , and 52\% of the Indian respondent companies said that they had acquired new customers using social networks while 35\% American companies managed that. Many companies are coming big way for Social Media Optimization for their Product or Services nowadays. During Election 2009 Social Media was used for Influence Indian Voters. Social Media Marketing in India is being undertaken by brands like Tata Docomo, MTV India, Channel V, Clear Trip, Tata Photon, Axe deodorants, Microsoft, Naukri, Shaadi and many more. Besides, numerous Indian celebrities are also using SMM platform to promote their movies, music and events via Twitter, Facebook and personalized blogs. Social Media Marketing is also boosting public relations business. Several PR agencies in India are undertaking brand building exercises for corporate organizations, brands and celebrities. However, to the delight of many among us, the biggest gainers from SMM till date have been the organizations from the Not-forProfit sector. Several Campaigns like 'Bell Bajao' and 'Jaago Re' have been quite successful on Social Networking Sites. These campaigns have been spreading the word about their cause through blogs, Twitter and Facebook. 


\subsection{Social Media Marketing Strategies}

SMM is still in its infancy. Most of the online retailers though appreciate its positives fallouts on the brand awareness and promotion; they are still in the early stages of adoption. For an organization willing to invest in social media marketing, it is important to understand why SMM is an important marketing strategy and how it can help:

- This is the age of consumer satisfaction. It is not about selling it is more about interacting. There is a lot to learn from the customers. Using social media one can identify customers, listen to their feedback and use them to improve and innovate on products or services.

- SMM is not a mass advertising strategy. It can be used to identify peer groups and advertise to that particular group. Social Media can help in identifying influencers and through them one can guide a prospective customer into making a purchase.

- SMM calls for novel advertising methods as the attention span of online junta is very low. This is largely due to the multitasking phenomena. A person watching a video clip on YouTube might be simultaneously updating a blog, while reading another one and watching friend's photographs on Facebook. In order to garner their attention away from distractions the advertisement must be innovative and interesting to hold the imagination and attention of the prospect.

- At the same time the message must also provoke the recipient into action; like seeking a detailed description of the product/service, or suggesting to a friend, or initiating purchase. So, if the advertisement is trying to sell something then it should be conveniently placed with links so that the prospect can make a purchase with least effort.

- Similarly Social Media can be used to increase customer loyalty through customer support services and hence improve customer retention.

- Social Media Marketing can also be used by brands to ward off any negative publicity. But the brands will have to be cautious here as over doing it may further aggravate their customers / stakeholders.

Companies using traditional marketing methods (e.g. surveys, focus groups, test marketing) often spend millions to locate their target markets. Establishing a social media strategy will help them see where potential customers are hanging out. The companies can search for related groups and Fan Pages through Facebook, start accounts on social bookmarking sites such as Digg or StumbleUpon, and check on who is linking to your site to find out who's interested.

Social media gives businesses on small budgets the ability to find out what people are saying about them (and others) in their industry, without paying large sums on market research. With its ear to the ground on social media, the company will be the first to know if its product is working or if changes need to be made.

To successfully implement one's SMM strategy the following points must be kept in mind:

- The company shouldn't just jump on to the bandwagon just because others are jumping into it. The market should be analyzed first to understand whether their brand would really benefit from SMM. It should try and find out whether SMM strategies fit its brand.

- The company shouldn't expect results over night. SMM is a long term strategy. It will not happen overnight. The results might become visible anywhere from three to six months.

- SMM is not a standalone tool for marketing. It has to be used along with all the other conventional marketing strategies.

There are many things that social media can do for business. Developing a strategy for using it means that the firms need to think about what they want to accomplish this year and 
determine how social media fits into the plan. One of the benefits of a social media strategy is the fact that the available tools can customized for their particular needs. The firms can choose to concentrate their efforts on the sites that seem to offer the best return on investment, while taking a "wait and see" stand on the others.

\section{CONCLUSION}

There is no escaping social media these days, either for individuals or for businesses. Today, it is impossible to separate social media from the online world.

The social media conversation is no longer considered a Web 2.0 fad -- it is taking place in homes, small businesses and corporate boardrooms, and extending its reach into the nonprofit, education and health sectors. From feeling excitement, novelty, bewilderment, and overwhelmed, a growing number of people now speak of social media as simply another channel or tactic. Blogging can have a very positive effect on your Company's branding \& growth. As per the Hubspot report, Customers with blogs gathered 68\% more leads than customers without blogs. It is imperative to understand that today, social media have exponential potential. They are part of an ever-growing online network of people who discuss, comment, participate, share and create.

Whether you are an individual, a startup, small business or a large corporation, an online presence and an ongoing conversation with your constituents is a baseline requirement - and will take time and expertise. Companies are diverting resources and rethinking their traditional outreach strategies. And as the social media wave dissipates into the vast ocean of connected experiences, the term itself will become an entry in dictionaries and encyclopedias and we will embark on a new era of knowledge, accessibility and experiences unbound by distance, time or physical walls. It is high time that every business adopts social media and takes it seriously!

\section{REFERENCES}

[1] Kaplan, Andreas M.; Michael Haenlein (2010). "Users of the world, unite! The challenges and opportunities of Social Media". Business Horizons 53 (1): 59-68. doi:10.1016/j.bushor.2009.09.003. ISSN 0007-6813. http://www.sciencedirect.com/ science/article/B6W45-4XFF2S0-1/2/600db1bd6e0c9903c744aaf34b0b12e1. Retrieved 2010-09-15.

[2] Lazer, W., Kelley, E.J. (1973). Social Marketing: Perspectives and Viewpoints. Homewood: Richard D. Irwin

[3] Michael A. Stelzner (2010), Social Media Marketing Industry Report, "How Marketers are using social media to grow their businesses", Social Media Examiner, April 2010

[4] Nora Ganim Barnes, Eric Mattson, "Still Setting the Pace in Social Media: The First Longitudinal Study of Usage by the Largest US Charities", University of Massachusetts Dartmouth Center for Marketing Research, 2008

[5] Social Media in India - An Overview by techiedevil on June 11, 2010 in Social Media http://www.internetmarketingjournal.org/social-media-india/

[6] http://www.zitzsolutions.com/internet-marketing-services/social-mediaoptimizationmarketing/

[7] http://www.analectic.org/social-media-marketing-brands-india/

[8] http://www.analectic.org/brand-engagement-on-social-media-industry-perspective/

[9] http://www.socialmediaexaminer.com/3-new-studies-prove-social-mediamarketinggrowth/\#more-2583 


\section{Vinod Durgam}

[10] https://www.statista.com/statistics/271408/share-of-social-media-in-online-advertisingspending-worldwide/

[11] https://www.emarketer.com/content/emarketer-total-media-ad-spending-worldwide-willrise-7-4-in-2018 